\title{
SURFACE ROUGHNESS STUDY OF UNS A97050-T7 BARS OBTAINED BY DRY TURNING
}

\author{
De Agustina, B.; Marin, M. \& Rubio, E.
}

Abstract: The main goal of this study is to analyse the relationship between the surface roughness obtained during the dry turning of aluminium UNS A97050-T7 bars and the cutting parameters (cutting speed and feed) using tools with coating of TiN. The followed methodology consisted of a series of short tests (no longer than 10 seconds) for different values of the cutting parameters that mentioned above. The principal result was that the surface quality, improves mainly with the descent of the feed and, to a lesser extent, with the increase of the cutting speed. As a first conclusion, it would be convenient to carry out new tests using values of the nearer feed to the values that have lead to obtain the best surface quality in this study.

Key words: dry turning, UNS A97050-T7, cutting parameters, surface roughness
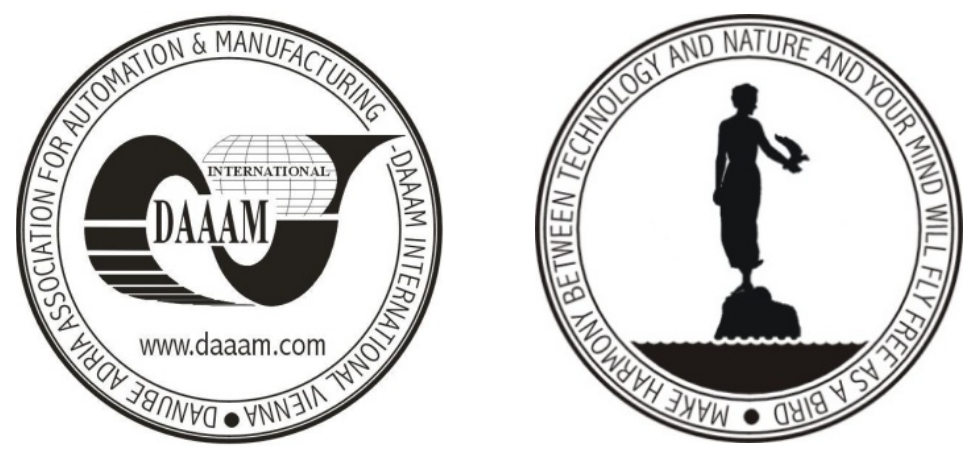

Authors' data: Research and teaching staff, De Agustina, B[eatriz]; Research and teaching staff. Marín, M[arta]; Dr. Rubio, E[va], National Distance University of Spain (UNED), Department of Manufacturing Engineering, C/ Juan de Rosal 12, E28040 Madrid, bdeagustina@ind.uned.es

This Publication has to be referred as: De Agustina, $\mathrm{B}$ [eatriz]; Research and teaching staff. Marín, M[arta] \& Dr. Rubio, E[va] (2009). Surface Roughness Study of UNS A97050-T7 Bars Obtained by Dry Turning, Chapter 90 in DAAAM International Scientific Book 2009, pp. 923-930, B. Katalinic (Ed.), Published by DAAAM International, ISBN 978-3-901509-69-8, ISSN 1726-9687, Vienna, Austria DOI: $10.2507 /$ daaam.scibook.2009.90 